\title{
Automation of Electrical Energy Savings System: Hemat Listrik, Hemat Biaya
}

\author{
A A Gde Satia Utama ${ }^{*}$, Naula Malda Janani², Silfiana ${ }^{3}$, Tri Nur Afiyah Wulandari ${ }^{4}$, \\ Budiningtyas ${ }^{5}$
}

1,2,3,4,5Fakultas Ekonomi dan Bisnis, Universitas Airlangga, Surabaya-Indonesia

\section{A R T I C L E I N F O \\ Article history: \\ Received 18 September 2018 \\ Received in revised form 10 October 2018 \\ Accepted 20 November 2018 \\ Available online 12 \\ December 2018 \\ Kata Kunci: \\ Otomatis dan System dan Listrik \\ Keywords: \\ Automatic and System and Electricity}

\begin{abstract}
A B S T R A K
Kesadaran masyarakat untuk berhemat energi listrik masih rendah. Penggunaan listrik yang berlebihan dan tidak sesuai kebutuhan sering terjadi dikalangan masyarakat seperti penggunaan listrik ruangan perkuliahan yang telah selesai. Automation of Electrical Energy Savings System merupakan aplikasi hasil pengembangan dari sistem otomatis berbasis mikrokontroler. Aplikasi ini dikendalikan oleh pihak-pihak yeng bertanggungjawab terhadap suatu ruangan melalui pengaturan jadwal pemakaian ruangan. Cara kerja aplikasi ini, secara otomatis ruangan yang terpasang sistem otomatis berbasis mikrokontroler akan menyesuaikan penggunaan listriknya sesuai dengan pengaturan jadwal lamanya penggunaan ruangan pada Automation of Electrical Energy Savings System. Dengan adanya aplikasi ini dapat mempermudah pengguna ruangan atau masyarakat dalam mengendalikan penggunaan energi listrik untuk tujuan penghematan.
\end{abstract}

Public awareness to save electricity is still low. Excessive use of electricity and not in accordance with needs often occurs among the community such as the use of electricity in the lecture hall that has been completed. The Automation of Electrical Energy Savings System is an application resulting from the development of an automatic system based on a microcontroller. This application is controlled by the parties responsible for a room through setting a room usage schedule. The way this application works, automatically the room installed with an automatic system based on a microcontroller will adjust its electricity usage according to the schedule for the length of use of the room on the Automation of Electrical Energy Savings System. With this application, it can facilitate room users or the public in controlling the use of electricity for savings purposes.

Copyright (c) Ekuitas: Jurnal Pendidikan Ekonomi. All rights reserved.

\footnotetext{
* Corresponding author.

E-mail addresses: gde.agung@feb.unair.ac.id (A A Gde Satia Utama)
} 


\section{Pendahuluan}

Kesadaran masyarakat untuk berhemat energi listrik masih rendah. Terlebih serangkaian studi awal memperlihatkan kelompok usia remaja menjadi kelompok yang dianggap tidak peduli terhadap upaya penghematan. Disamping merasa tidak bertanggungjawab atas pembayaran listrik, para remaja beranggapan tidak tahu alasan mengapa harus berhemat listrik. Faktor penyebab lain, masyarakat menganggap perilaku hemat energi listrik akan mengurangi kenyamanan dan kesenangan, dan mereka juga beranggapan isu kelangkaan energi hanyalah isu yang dipolitisasi dan kelangkaan energi lebih disebabkan kegagalan pemerintah dalam mengelola energi.

Penggunaan listrik yang berlebihan atau boros sering kita jumpai dalam kehidupan masyarakat seperti lampu yang tidak dimatikan meskipun sudah pagi, lampu yang dibiarkan menyala saat sedang tidur dan dalam entitas pendidikan sering dijumpai lupa mematikan pendingin ruangan setelah selesai digunakan serta LCD proyektor yang dibiarkan tetap menyala meski kegiatan peruliahan telah selesai. Hal ini dapat terjadi karena masyarakat kita tidak terbiasa dengan perilaku hemat energi sehingga perlu adanya kebiasaan disiplin dalam menggunakan energi listrik tersebut.

Dengan adanya permasalahan seperti yang diuraikan diatas maka dibutuhkan sebuah sistem atau alat yang dapat digunakan secara otomatis untuk menyalakan atau memadamkan aliran listrik sehingga penggunaan listrik dapat diatur dan terjadi penghematan dalam penggunaannya. Dari uraian tersebut permasalahan yang muncul adalah bagaimana mekanisme kerja sistem automation of electrical energy savings system dalam penghematan energi listrik.

\section{Pengertian Risk Of Project Information Systems}

Faktor kegagalan utama sebuah proyek sistem iformasi adalah tidak memiliki perencanaan yang jelas dan terintegrasi, kebutuhan informasi yang tidak jelas, kurangnya keterlibatan pemakai dalam perencanaanya, kurangnya ketersediaan sumberdaya sistem informasi, harapan pengguna yang tidak realistis, kurangnya dukungan dari pimpinan puncak atau manajemen senior, perubahan kebutuhan terhadap hasil proyek, kurangnya kemampuan mengelola teknologi informasi dan rendahnya pemahaman mengenai perangkat teknologi informasi (Bridge, 2002).

Hakekatnya sebuah proyek sistem informasi memiliki sistem-sistem yang berbeda jauh, baik dari segi ukuran, cakupan, kerumitan, serta komponen organisasional dan teknisnya. Tingkat resiko proyek sistem informasi dipengaruhi oleh ukuran proyek, dan tingkat keahlian teknis dan staf sistem informasi dan tim proyek (Schwalbe, 2005).

Semakin besar ukuran sebuah proyek sistem informasi, seperti yang diindikasikan oleh pengeluaran uang, jumlah staf implementasi, waktu yang dialokasikan untuk implementasi, dan keterlibatan sejumlah unit organisasional perusahaan akan berpengaruh kepada semakin besar resikonya. Kejelasan struktur proyek sistem informasi juga berpengaruh kepada proses bisnis perusahaan ( Taylor, 2004). Selanjutnya kemampuan berupa keahlian teknis yang melekat kepada tim pengembang proyek juga menentukan risiko kegagalan sebuah proyek sistem informasi (O’brien 2007). Kegagalan pengadaan proyek sistem informasi juga berasal dari kurangnya kapsitas manajerial dan keterampilan inti yang sesuai (McLeod et.al.,2007).

\section{Sensor PIR}

Pancaran infra merah masuk melalui lensa fresnel dan mengenai sensor pyroelektrik, karena sinar infra merah mengandung energi panas maka sensor pyroelektrik akan menghasilkan arus listrik. Sensor pyroelektrik terbuat dari bahan galium nitrida (GaN), cesium nitrat (CsNo3) dan litium tantalate (LiTaO3). Arus listrik inilah yang akan menimbulkan tegangan dan dibaca secara analog oleh sensor. Kemudian sinyal ini akan dikuatkan oleh penguat dan dibandingkan oleh komparator dengan tegangan referensi tertentu (keluaran berupa sinyal 1-bit). Jadi sensor PIR hanya akan mengeluarkan logika 0 dan 1,0 saat sensor tidak mendeteksi adanya pancaran infra merah dan 1 saat sensor mendeteksi infra merah. Sensor PIR didesain dan dirancang hanya mendeteksi pancaran infra merah dengan panjang gelombang 8-14 mikrometer. Diluar panjang gelombang tersebut sensor tidak akan mendeteksinya. Untuk manusia sendiri memiliki suhu badan yang dapat menghasilkan pancaran infra merah dengan panjang gelombang antara 9-10 mikrometer (nilai standar 9,4 mikrometer), panjang gelombang tersebut dapat terdeteksi oleh sensor PIR. (Secara umum sensor PIR memang dirancang untuk mendeteksi manusia).

\section{Sensor Suhu LM 35}

Prinsip kerja alat pengukur suhu ini, adalah sensor suhu difungsikan untuk mengubah besaran suhu menjadi tegangan, dengan kata lain panas yang ditangkap oleh LM 35 sebagai sensor suhu akan diubah menjadi tegangan. Sedangkan proses berubahnya panas menjadi tegangan dikarenakan di dalam LM 35 
ini terdapat termistor berjenis PTC (Positive Temperature Coefisient), yang mana termistor inilah yang menangkap adanya perubahan panas. Prinsip kerja dari PTC ini adalah nilai resistansinya akan meningkat seiring dengan meningkatnya temperatur suhu. Resistansi yang semakin besar tersebut akan menyebabkan tegangan output yang dihasilkan semakin besar. LM35 adalah sensor suhu dari Texas Instruments Incorporated yang mempunyai akurasi tinggi. Outputnya berupa tegangan analog dan memiliki jangkauan pengukuran $-55^{\circ} \mathrm{C}$ hingga $+150^{\circ} \mathrm{C}$ dengan akurasi $\pm 0.5^{\circ} \mathrm{C}$. Tegangan output adalah $10 \mathrm{mV} /{ }^{\circ} \mathrm{C}$. Output dapat langsung dihubungkan port mikrokontroler yang memiliki ADC atau dengan Arduino, karena Arduino memiliki port ADC (analog input) sebanyak 6 buah.

\section{Mikrokontroler Arduino Uno R3}

Arduino Uno R3 dapat diaktifkan melalui koneksi USB atau dengan catu daya eksternal. Sumber daya dipilih secara otomatis. Untuk sumber daya Eksternal (non-USB) dapat berasal baik dari adaptor ACDC atau baterai. Adaptor ini dapat dihubungkan dengan memasukkan $2.1 \mathrm{~mm}$ jack DC ke listrik board. Baterai dapat dimasukkan pada pin header Gnd dan Vin dari konektor daya. Board dapat beroperasi pada pasokan eksternal dari 6 sampai 20 volt. Jika menggunakan tegangan kurang dari 6 volt mungkin tidak akan stabil. Jika menggunakan lebih dari $12 \mathrm{~V}$, regulator tegangan bisa panas dan merusak papan. Rentang yang dianjurkan adalah 7 sampai 12 volt. Untuk pemrograman rangkaian kontrol ini menggunakan program bahasa c. Setelah program di buat dan di simpan kemudian program di upload dari komputer melalui software Arduino 1.0.5 ke Board Arduino Uno R3 berikut data program kontrol pemanfaatan sistem sensor untuk menghemat energi listrik pada gedung.

Tabel 1. Penelitian Terdahulu

\begin{tabular}{|c|c|c|c|c|c|}
\hline No & Nama & Judul & Tahun & Jenis & Hasil Penelitian \\
\hline 1 & $\begin{array}{l}\text { M. Zaky } \\
\text { Zaim } \\
\text { Muhtadi }\end{array}$ & $\begin{array}{l}\text { Analisis Peluang } \\
\text { Penghematan } \\
\text { Energi Listrik pada } \\
\text { Sistem Pencahayaan } \\
\text { Gedung Jteti Ugm }\end{array}$ & 2016 & $\begin{array}{l}\text { Kualita } \\
\text { tif }\end{array}$ & $\begin{array}{l}\text { Hasil penelitian ini menunjukan } \\
\text { bahwa hasil sebagai berikut: (1) } \\
\text { peluang penghematan energi listrik } \\
\text { per bulan pada sistem tata cahaya } \\
\text { sebesar } 2.320,318 \text { kWh }(20,8 \%) \\
\text { dengan melakukan penggantian } \\
\text { luminer dan ballast elektronik, (2) } \\
\text { rata-rata prilaku responden terhadap } \\
\text { penghematan energi listrik pada } \\
\text { sistem pencahayaan adalah baik } \\
\text { sebesar 79,4\%, (3) waktu yang } \\
\text { dibutuhkan untuk pengembalian } \\
\text { investasi adalah } 76 \text { bulan sehingga } \\
\text { pelaksaan retrofitting pada sistem } \\
\text { pencahayaan tidak layak. Oleh karena } \\
\text { itu, retrofitting hanya dianjurkan } \\
\text { dilakukan pada peralatan lama yang } \\
\text { rusak saja. }\end{array}$ \\
\hline
\end{tabular}

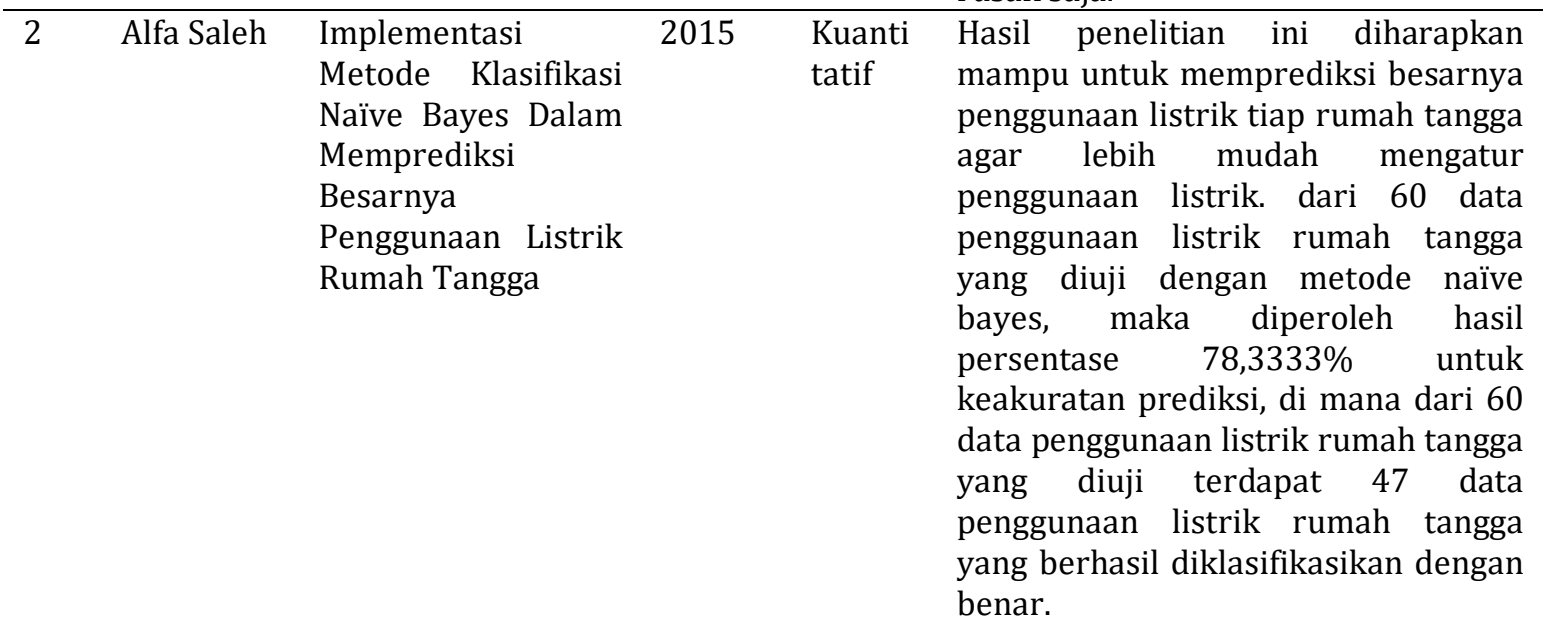

\begin{tabular}{|c|c|c|c|c|c|c|}
\hline 3 & $\begin{array}{l}\text { Deni } \\
\text { Almand,Kr }\end{array}$ & $\begin{array}{l}\text { Manajemen } \\
\text { Konsumsi }\end{array}$ & Energi & 2017 & $\begin{array}{l}\text { Kualita } \\
\text { tif }\end{array}$ & Dengan menggunakan sistem ini \\
\hline
\end{tabular}




\begin{tabular}{|c|c|c|c|c|}
\hline & $\begin{array}{l}\text { isdianto } \\
\text { dan Erwin } \\
\text { Dermawa } \\
\mathrm{n}\end{array}$ & $\begin{array}{l}\text { Listrik Dengan } \\
\text { Menggunakan } \\
\text { Sensor Pir Dan Lm } \\
35\end{array}$ & & $\begin{array}{l}10 \% \text { akan tercapai bahkan bisa } \\
\text { mencapai } 50 \% \text { dibanding sistem } \\
\text { operasi manual secara umum pada } \\
\text { gedung bertingkat }\end{array}$ \\
\hline 4 & $\begin{array}{l}\text { Temy } \\
\text { Nusa, } \\
\text { Sherwin } \\
\text { R.U.A. } \\
\text { Sompie, } \\
\text { ST.,MT. } \\
\text { dan } \\
\text { Dr.Eng } \\
\text { Meita } \\
\text { Rumbaya } \\
\text { n, ST.,MT. }\end{array}$ & $\begin{array}{lrr}\text { Sistem } & \text { Monitoring } & 2015 \\
\text { Konsumsi } & \text { Energi } & \\
\text { Listrik Secara Real } & \\
\text { Time } & \text { Berbasis } \\
\text { Mikrokontroler }\end{array}$ & $\begin{array}{l}\text { Kuanti } \\
\text { tatif }\end{array}$ & $\begin{array}{l}\text { Pada pengujian yang dilakukan, } \\
\text { diketahui hasil pengukuran konsumsi } \\
\text { energi listrik menggunakan alat yang } \\
\text { telah dirancang mampu mengukur } \\
\text { arus listrik dengan cukup teliti pada } \\
\text { beban resistif murni dengan error } \\
\text { lebih kecil dari 1\%, akan tetapi terjadi } \\
\text { error pada beban lampu LED } \\
\text { SiCermat sebesar 14,30\%, juga pada } \\
\text { beban Lampu Philips Softone sebesar } \\
5,73 \% \text { jika dibandingkan dengan } \\
\text { pengukuran menggukan Multimeter } \\
\text { Krisbow KW06-276. }\end{array}$ \\
\hline
\end{tabular}

\section{Metode}

Pembuatan system ini dilakukan dengan metode waterfall. Waterfall adalah suatu proses pengembangan perangkat lunak berurutan, dimana kemajuan dipandang sebagai terus mengalir ke bawah, melaewati fase-fase perencanaan, pemodelan, implementasi dan pengujian.

\section{Perencanaan}

Fase ini merupakan fase dimana peneliti melakukan dan membuat perencanaan pembuatan system. Perencanaan ini meliputi penentuan tujuan digunakannya system, pembuatan strategi, hingga mekanisme penggunaan system ini.

\section{Design System / pemodelan}

System ini akan dioperasikan di seluruh ruangan tatap muka entitas pendidikan, dengan bantuan alat timer otomatis yang sudah menjadi sau bagian dengan sistem penghemat energi listrik ini. System ini dibantu oleh sensor PIR yang terdiri dari 4 PIR. PIR 1//PIR 2 akan mendeteksi sensor pencahayaan lampu dan PIR 3 akan mendeteksi Proyektor serta PIR 4 + LM35 untuk sensor penyejuk ruangan (AC).

\section{Implementasi}

Fase ini merupakan fase penting dalam proses pengaplikasian system.Fase ini berhasil tidaknya implementasi Automation of Electrical Energy Savings System akan memberikan dampak yang berpengaruh terhadap keberlanjutan system ini.

\section{Pengujian}

Fase ini merupakan fase terakhir sebelum system ini akan diaplikasikan secara permanen. System ini akan diuji tingkat resiko yang ditimbulkan hingga pengujian mengenai jangka waktu penerapan system ini.

\section{Hasil dan pembahasan}

Mekanisme kerja sistem automation of electrical energy savings system dalam penghematan energi listrik Sistem kerja alat penghemat listrik ini sangat membantu sebuah entitas pendidikan dalam mengestimasi dan menetapkan beban listrik. Jika penggunaan listrik yang telah diterapkan sebelumnya secara manual yaitu disesuaikan dengan jam kerja operasional, sering terjadi kesulitan dalam menentukan dan mengkalkulasi beban listrik yang digunakan. Dengan adanya bantuan system penghematan listrik secara otomatis ini, tingkat keakurasian estimasi beban listrik menjadi tinggi, karena cara kerja sistem ini dilengkapi dengan sistem otomasi yang telah diatur sebelumnya sesuai kebutuhan pemakaian. 


\title{
Kebutuhan Mutlak dalam Pembuatan Sistem
}

Pertama, Sumber daya: Operator sistem ini diotorisasi oleh bagian sarana dan prasarana, Listrik dan media yang berdaya listrik (AC, Lampu dan Proyektor), dan Timer otomatis yang menjadi satu bagian dengan sistem.

Kedua, Software. Sistem ini dirancang oleh programer yang juga memiliki spesifikasi dibidang listrik dan elektronik dengan bentuk sebuah expert system berbasis otomasi yang terintegrasi. Yang memiliki berbagai menu dalam pengaturan pengguanaan ruangan, diantaranya : Pengisisan identitas penanggungjawab pengguna ruangan meliputi : nama, no identitas, alamat, no HP, Profil Ruangan, Keperluan penggunaan ruangan dan kapasitas pengguna, dan Pengaturan waktu penggunaan ruangan meliputi waktu mulai dan durasi penggunaan.

Ketiga, Hardware. Sistem ini dirupakan dalam bentuk hardware serupa dengan tampilan pada hardware fingerprint.

\author{
RANCANGAN DFD \\ Automation of Electrical \\ Energy Savings System
}

\begin{tabular}{|c|}
\hline ID SARPRAS \\
\hline NAMA : \\
\hline NO ID : \\
\hline WAKTU : \\
\hline ALAMAT : \\
\hline
\end{tabular}

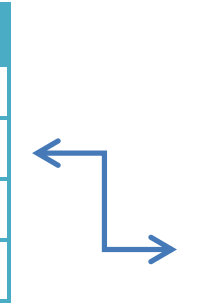

\begin{tabular}{l} 
KARTU RUANGAN \\
(untuk penanda ruangan \\
terpakai) \\
NAMA : : \\
\hline NOMOR : \\
\hline USER : \\
\hline PENANGGUNGJAWAB :
\end{tabular}

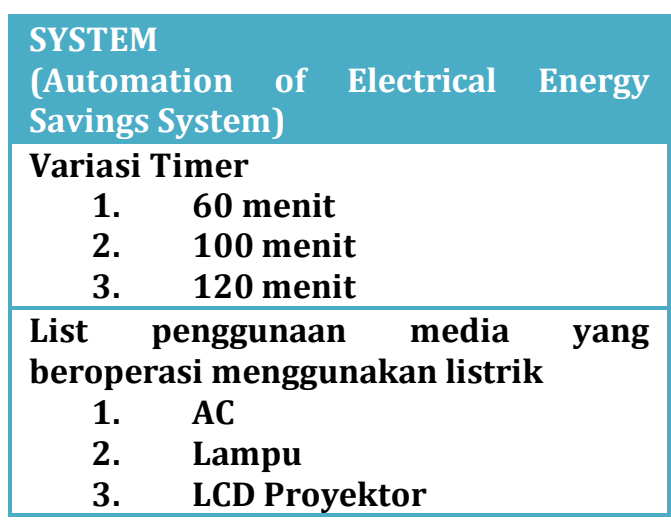

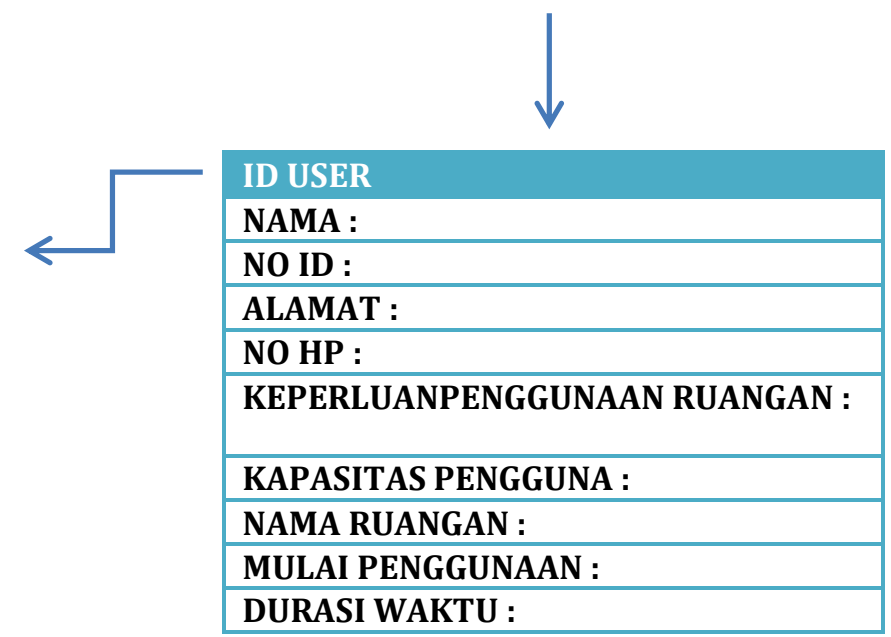

Gambar 1. Automation of Electrical Energy Savings System

\section{Analisis dan Pengujian}

Analisis Sistem

Sistem ini bekerja secara otomatis dan dilengkapi oleh RFID sensor nirkabel yang mendukung cara kerja yang dapat mulai beroperasi ketika sensor bekerja. Sistem ini dimulai mendeteksi keberadaan seseorang yang berada di dalam ruangan, jika iya maka secara otomatis listrik dalam ruangan akan beroperasi mengikuti pengaturan ruangan yang telah diatur sebelumnya. 
Operator sistem berada pada tanggungjawab bagian sarana dan prasarana entitas pendidikan. Selain itu sistem ini dapat berjalan beriringam dengan pengawasan secara integrasi. Implementasi sistem ini setelah dirasa sudah berjalan secara efektif dan efisien sesuai tujuan awal diciptakannya, sistem ini juga akan mendapatkan pemeliharaan secara berkala untuk tetap memastikan sistem berjalan sesuai prosedur dan antisipasi terjadinya konslet dan eror.

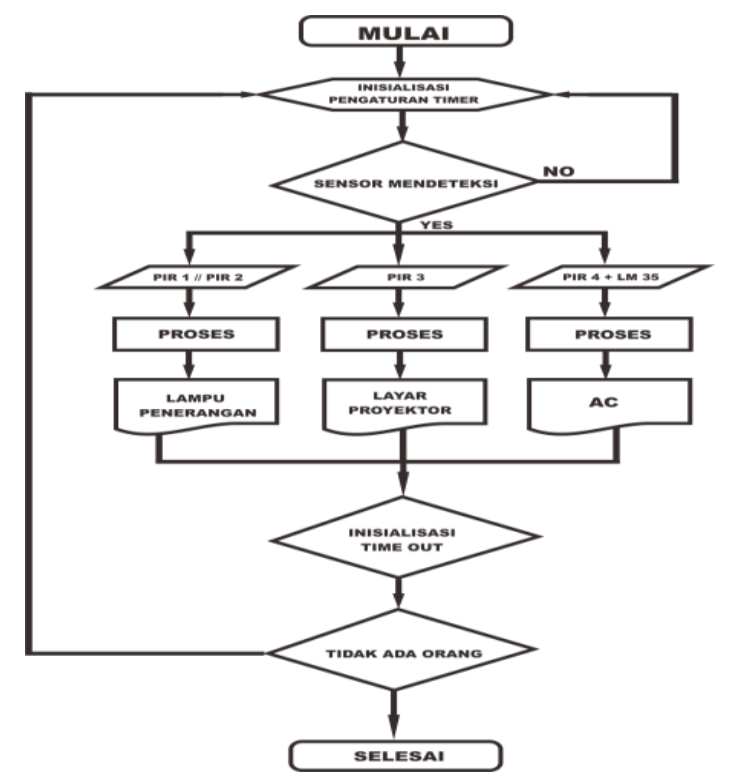

Gambar 2. Rancangan diagram alur operasi system

Cara kerja system ini adalah terintegrasi yang diotorisasi oleh bagian Sarana Prasarana. Desain prosedur penggunaannya adalah sebagai berikut

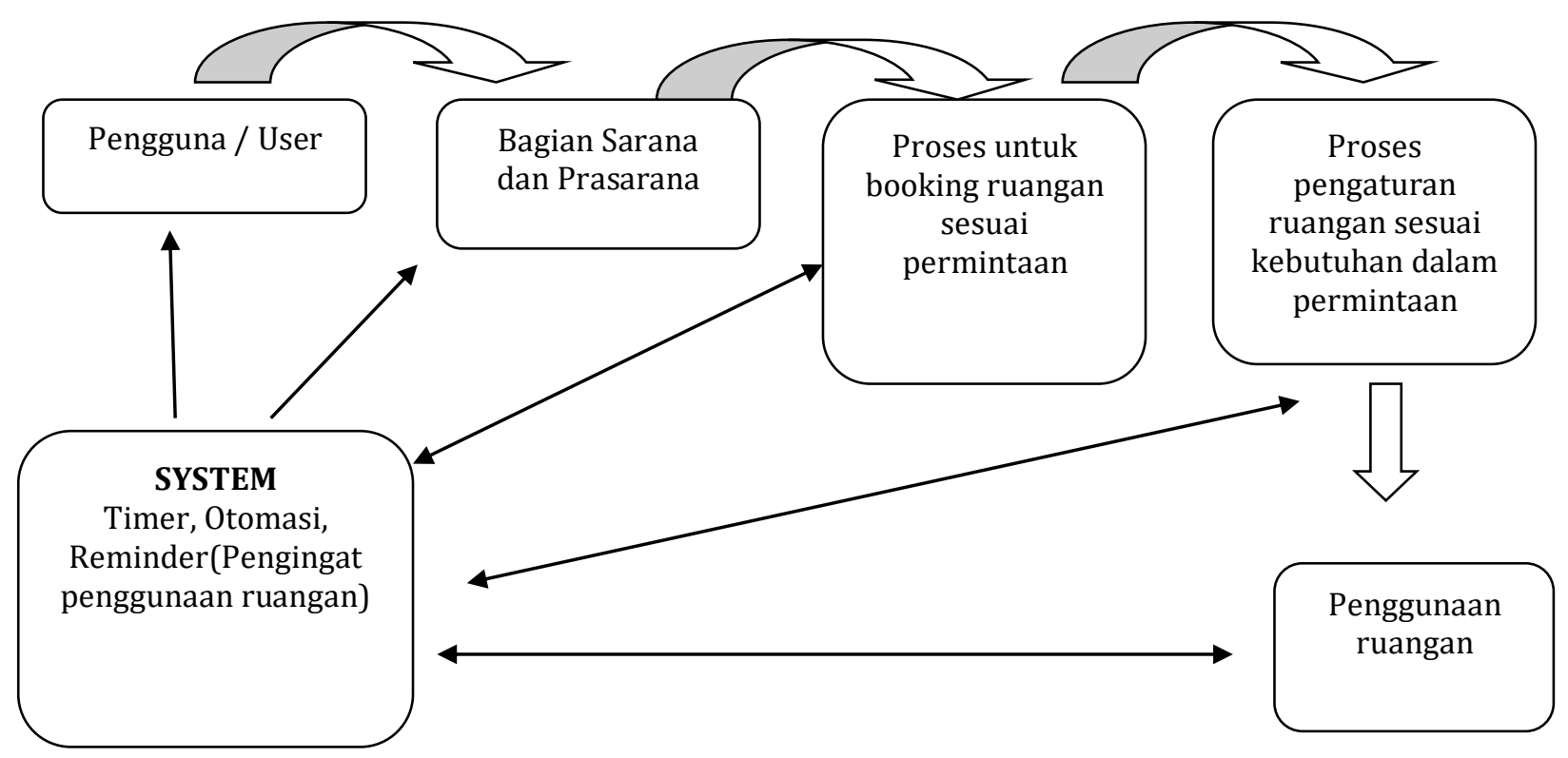

Gambar 3. Rancangan diagram alur operasi sistem

\section{Analisis Kendala Pengembangan Sistem}

Pertama, Sumber Daya Manusia. Sistem ini memerlukan SDM yang konsisten dan tingkat ketelitiannya tinggi serta komunikatif. Dan yang paling penting mengerti proses dan alr jalannya sistem ini. Bagian Sarana dan Prasarana wajib memiliki kualifikasi yang telah disebutkan untuk tetap bisa mengontrol dan memonitoring aktivitas dari sitem ini. 
Kedua, Harga/Biaya. Untuk mencapai sistem yang dapat diaplikasikan secara integrasi serta efisien ini perlu modal pendanaan yang signifikan, karena proses yang sangat panjang mulai dari persiapan, perizinan, pencarian data melalui survei dan estimasi analisis data yang perlu dilakukan percobaan secara berulang. Karena bersangkutan dengan penggunaan listrik yang terintegrasi.

Ketiga, Adaptasi. Munculnya sistem ini secara conversi yaitu dapat berjalan beriringan dengan sistem yang sebelumnya. Perlunya sosialisasi, training dan praktik yang diulang-ulang bagi pengguna sistem ini demi tercapainya tujuan adanya sistem ini yaitu penghematan energi listrik dengan penggunaan listrik yang sesuai kebutuhan. Bagi pengguna, akan merasa terbatasi dalam penggunaan ruangan di setiap aktivitasnya.

Keempat, Infrastruktur. Entitas pendidikan di Indonesia masih banyak yang belum melek teknologi, dengan kata lain. Sistem ini dapat diimplementasikan secara bertahap hingga semua elemen pendukung mulai deri teknologi, sosial dapat terpenuhi.

Kelima. Timelines. Finishing dari sistem ini membutuhkan waktu yang lumayan panjang, sehingga kebutuhan dalam sistem ini perlu menjadi strategy prioritas dalam pemenuhannya.

\section{Analisis Resiko}

Pertama, Kurangnya keterlibatan pemakai dan perencananya. Implementasi Automation of electrical energy savings systems akan jarang sekali melibatkan perencana dalam penggunaannya. Hal ini menjadi ancaman bagi sitem ini sendiri, karena sistem ini seharusnya dioperasikan oleh pencipta secara langsung agar tetap bisa dapat dikendalikan dan kemungkinan gagal itu kecil.

Kedua, Harapan pengguna yang tidak realistis. Diawal implementasi sistem ini akan banyak miss antara pengguna dan perencana. Sehingga harapan-harapan bagi engguna cenderung susah dipenuhi dengan adanya sistem ini. Misal : budaya disiplin waktu pelajar dan mahasiswa di indonesia sangat rendah, dengan hadirnya sitem ini akan memberikan banyak batasan terhadap pengguna sistem dalam setiap aktivitasnya yaitu (waktu istirahat terbatas ).

Ketiga, kurangnya kemampuan mengelola teknologi informasi ketika operasional sistem ini di kelola oleh SDM yag kurang memiliki keahlian teknis, maka menjadi sebuah ancaman bagi keberlangsungan sistem ini.

Kelima, Rendahnya pemahaman mengenai perangkat teknologi informasi entitas pendidikan yang masih menggunakan sistem manual dalam upaya penghematan listrik, akan memerlukan waktu untuk bisa memahami dan dapat menerima serta beradaptasi dengan keadaan yang baru yang telah diciptakan stelah adanya sistem ini.

\section{Analisis Cost Dan Benefit \\ Analisis Biaya} meliputi :

Dalam perencanaan pembuatan sistem akan melalui beberapa tahapan, tahapan-tehapan tersebut

Pertama, Persiapan dan Perizinan. Dalam tahap ini akan mengeluarkan biaya untuk perizinan yang digunakan untuk pnlitian. Penelitian ini dilakukan di sebuah gedung percobaan.

Kedua, Pengumpulan Data. Tahap ini akan dibagi menjadi 3 sumber data yaitu: Data ruang gedung, Data sistem tata ruang, cahaya dan meia berdaya listrik, dan Data pra survei dan survei. Dalam tahap ini akan diperlukan bantan sumbar daya manusia yang memiliki kualifikasi sesuai pembagian data, mulai dari ahli pemerhati gedung, ahi elektrik/listrik dan teknisi serta enumerator dalam pengumpulan data survei. Kebutuhan yang telah disebut diatas juga memerlukan biaya yang lumayan tinggi, karena dalam proses pengumpulan data juga menghabiskan waktu yang lumayan panjang. Sehingga biaya akan meningkat. Hingga sumber data tersebut dikelola dan menjadi informasi yang dapat digunakan dalam proses selanjutnya.

Ketiga, Analisis biaya Investasi dan pengembalian. Dalam pembuatan sistem ini perlulah untuk mengestimasikan biaya yag dikeluarkan dalam investasi berupa asset yaitu sistem ini dan mengkalkulasi tingkat pengembalian oleh perencana dan pemilik. Agar dalam implementasinya dapat berjalan lancar dan benefit yang akan diterima sesuai dengan rencana yang telah dicanangkan.

Keempat, Pengadaan Infrastruktur pembuatan System. Pembelian infrastruktur mulai dari percobaan hingga praktik.

Kelima, Biaya pengembangan system. Setelah praktik sistem akan perlu adanya pengembangan agar dalam proses berjalannya aktivitas pada sistem ini selalu update.

Keenam, Biaya pemeliharaan system. sistem ini akan memerlukan biaya pemeliharaan mulai dari lisensi hingga perbaikan sistem.

\section{Analisis Manfaat}


Automation of electrical energy savings systems diciptakan sebagai salah satu upaya penghematan penggunaan energi listrik berbasis otomasi dengan kesadaran melalui disiplin waktu. Praktik sistem ini akan memberikan sejumlah manfaat bagi generasi mendatang yaitu penghematan listrik. Bagi generasi sekarang juga dapat melatih kedisiplinan waktu dalam setiap ativitas yang dijalani serta bagi entitas pendidikan adalah meringankan biaya beban listrik dalam operasionalnya.

Dari sekian banyak biaya yang akan dikeluarkan, manfaat yang diperoleh juga memberikan ampak yang signifikan baik untuk generasi sekarang dan utamanya generai mendatang.

\section{Pengujian Sistem}

Setelah perancangan program, maka langkah selanjutnya dilakukan pengujian dan analisa terhadap hasil yang diperoleh. Pengujian dilakukan dengan mengatur standart variasi timer kebutuhan penggunaan ruangan yang dikehendaki. Pada perancangan sistem kendali yang dibangun menampilkan display dari sensor suhu, penerangan dan LCD Proyektor kemudian menampilkan display timer maksimum dan minimumnya. Serta yang terakhir menganalisa penghematan daya listrik sebelum dan sesudah menggunakan perancangan Automation of Electrical Energy Savings System.

\section{Keterbatasan System}

System ini hanya dirancang untuk ruangan-ruangan pertemuan. Ruangan pertemuan yang dimaksud adalah ruang belajar mengajar, ruangan rapat dan Aula. System ini dirancang dengan tujuan mengefidiensi penggunaan listrik dengan tujuan penghematan listrik di kalangan pendidik.

\section{Simpulan dan saran}

\section{Simpulan}

Dengan adanya system ini diharapkan dapat menggunakan energy listrik secara efisien, supaya bisa lebih bijak lagi dalam menggunakan energy listrik dan tidak digunakan secara boros.

\section{Saran}

Diharapkan dapat melakukan control secara terus menerus dengan adanya aplikasi ini, dengan cara bekerjasama dengan seseorang yang ahli dalam bidang IT, supaya aplikasi ini tetap terjaga dan tidak digunakan oleh sembarang orang.

\section{Daftar Rujukan}

Almanda, Deni, Krisdianto Krisdianto, and Erwin Dermawan. "Manajemen Konsumsi Energi Listrik Dengan Menggunakan Sensor PIR dan LM 35." eLEKTUM 14.1 (2017): 16-22.

Bridge, Williams, 2002. Managing Transition : making The Most Change, Nicholas Brealy.London.

Indah Fatmawati, S.E., M.M. Perilaku hemat Listrik di Kalangan Remaja Masih Rendah. FE UMY. Yogyakarta.

McLeod, Raymond Jr, and George P. Schell. 2007. Management

Information Systems. Eleventh Edition. Person Education International.

Muhtadi, Muhammad Zaky Zaim. "ANALISIS PELUANG PENGHEMATAN ENERGI LISTRIK PADA SISTEM PENCAHAYAAN GEDUNG JTETI UGM." Jurnal ESDM 6.1 (2016).

Nusa, Temy, Sherwin RUA Sompie, and Meita Rumbayan. "Sistem Monitoring Konsumsi Energi Listrik Secara Real Time Berbasis Mikrokontroler." E-journal Teknik Elektro dan Komputer4.5 (2015): 1926.

O’Brien, James A. And Marakas, George M..2007. Enterprise Information Systems.Thirteenth Edition .McGraw-Hill/Irwin International Edition. 
Saleh, Alfa. "Implementasi Metode Klasifikasi Naïve Bayes Dalam Memprediksi Besarnya Penggunaan Listrik Rumah Tangga." Creative Information Technology Journal 2.3 (2015): 207-217.

Schwalbe, Kathy. 2005. Information Technology Project Management. Fourth Edition, Course Technology.

Taylor, James. 2004. Managing Information Technology Projects : Applying Project Management Strategies to Software, Hardware, and Integration Initiatives. AMACOM. 